\title{
Antimicrobial Potential of Leaf juice and Extracts of Moringa oleifera lam against some Human pathogenic Bacteria.
}

\author{
${ }^{1}$ Stanley Chukwudozie Onuoha and ${ }^{2}$ Christopher Onyemeziri Alisa \\ ${ }^{I}$ Microbiology unit, Department of Science Laboratory Technology, Akanu Ibiam Federal Polytechnic, Unwana, \\ PMB 1007 Afikpo, Ebonyi State. ${ }^{2}$ Department of Chemical Sciences, Novena University, Ogume, Delta State.
}

\begin{abstract}
The antibacterial activity of ethanol, hot and cold water extracts of both fresh and dried leaves as well as the juice extracts of Moringa oleifera Lam. were obtained by standard disc diffusion methods against some human pathogenic bacteria; Staphylococcus aureus, Streptococcus faecalis, E. coli and Pseudomonas aeruginosa. The ethanol extracts of fresh leaves and dried leaves displayed a potential broad-spectrum activity against all the tested organisms, Staphylococcus aureus, Streptococcus spp, E. coli and Pseudomonas aeruginosa. Also, cold water extracts of fresh and dried leaves as well as hot water extracts of fresh and dried leaves inhibited the growth of the tested organisms with the exception of E. coli and Pseudomonas aeruginosa which were not inhibited by cold and hot water extract of fresh and dried leaves. The result of this study revealed that, the antibacterial activity of the extract could be enhanced if the components are purified. The plant therefore holds a promise as a potential source of new drugs for treating infections caused by these clinical pathogens.
\end{abstract}

Keywords: Antimicrobial, leaf juice, Moringa oleifera, Pathogenic bacteria.

\section{Introduction}

The frequency of life-threatening infections caused by pathogenic microorganisms has increased worldwide and is becoming an important cause of morbidity and mortality in immunocompromised patients in developing countries (Al-Bari et al., 2006). The increasing prevalence of multi-drug resistant strains of bacteria and the recent appearance of strains with reduced susceptibility to antibiotics raised the specter of untreatable bacterial infections and adds urgency to the search for new infection-fighting strategies (Rojas et al., 2006).

For a longtime, plants have been an important source of natural products for human health. The antimicrobial properties of plants have been investigated by a number of studies world-wide and many of them have been used as therapeutic alternatives because of their antimicrobial properties (Adriana et al., 2007). Plants have many antimicrobial properties as secondary metabolites such as alkaloids, phenolic compounds etc.

The practice of complementary and alternative medicine is now on the increase in developing countries in response to world health organization directives culminating in several pre-clinical and clinical studies that have provided the scientific basis for the efficacy of many plants used in folk medicine to treat infections (Dilhuydy, 2003). However, despite the existence of potent antibiotic and antifungal agents, resistant or multiresistant strains are continuously appearing, imposing the need for a permanent search and development of new drugs (Silver, 1993).

It is therefore very necessary that the search for newer antibiotic source be a continuous process. Plants are the cheapest and safer alternative sources of antimicrobials (Sharif and Banik, 2006; Doughari et al., 2007). Moringa oleifera Lam. is the most widely cultivated species of a monogeneric family, the moringaceae that is native to the sub-Himalayan tracts of India, Pakistan, Bangladesh, and Afghanistan (Fahey, 2005), is widely used for treating bacterial infections, fungal infection, anti inflammation, sexually-transmitted diseases, malnutrition and diarrhea. Moringa oleifera species is cultivated and use as vegetable (leaves, green pods, flowers, roasted seeds), for spice (mainly roots) for cooking and cosmetic oil (seeds) and as a medicinal plant (all plant organs) (Rebecca et al., 2006). The Moringa plant provides a rich and rare combination of zeatin, quercetin, kaempferon and many other phytochemicals. Various parts of the plant such as the leaves, roots, seeds, bark, fruits, flowers and immature pods act as cardiac and circulatory stimulants, possess antitumor (Makonnen et al., 1997), Antipyretic, antiepileptic, antinflammatory, antiulcer (Pal et al., 1995a). Other important medicinal properties of the plant include antispasmodic (Caceres et al., 1992), diuretic (Morton, 1991), antihypertensive (Dahot, 1998) cholesterol lowering (Mehta et al., 2003), antioxidant, anti diabetic, hepatoprotective (Ruckmani et al., 1998), antibacterial and antifungal activities (Nickon et al., 2003). In addition, M. oleifera seeds posses water purifying powers (Muyibi and Evison, 1995a, Kawo, 2007) by flocculating bacterial cells (kawo, 2007). M. oleifera seeds can also be used as a less expensive bioabsorbent for the removal of heavy metals (Sharma et al., 2006). 
The present study is to investigate the role of juice, aqueous and ethanolic extracts of Moringa oleifera leaves as potential antimicrobial agent against some human pathogenic bacteria.

\subsection{Collection and Identification of Plant Sample}

\section{Materials And Methods}

The fresh leaves of Moringa oliefera Lam. were collected from Federal College of Agriculture, Ishiagu Ebonyi State. The plant specimen were identified and authenticated by a taxonomist in the Department of Science Laboratory Technology, Akanu Ibiam Federal Polytechnic, Unwana.

\subsection{Preparation of the Extracts}

\subsubsection{Fresh Leaf juice Extract}

Twenty - five grams $(25 \mathrm{~g})$ of fresh leaves of M. oleifera Lam. were weighed out and crushed directly by grinder without adding any solvent, and leaf juice was collected in a clean airtight bottle, after which it was stored for antibacterial activity test.

2.2.2 Cold aqueous Extracts of Fresh and dried Leaves

Twenty - five grams $(25 \mathrm{~g})$ of fresh leaves of M. oleifera Lam. were weighed out and crushed directly by grinder and was suspended into $100 \mathrm{ml}$ of cold distilled water in a conical flask and was covered with rubber cork and left for 7 days with occasional shaking. It was filtered off on the $7^{\text {th }}$ day using sterile filter paper (Whattman no. 1) into another clean conical flask; it was subjected to water bath evaporation where the aqueous solvent was evaporated at its boiling temperature of $100^{\circ} \mathrm{C}$. The standard extracts obtained was then stored in the refrigerator at $4^{\circ} \mathrm{C}$ for antibacterial activity test. (Akueshi et al., 2002).

In another case, the well air-dried fresh leaves was ground and $25 \mathrm{~g}$ was weighed out and was dipped into $100 \mathrm{ml}$ cold distilled water in a conical flask stoppered with rubber corks and was left for 7 days with occasional shaking. The other steps were the same as followed in case of cold water extracts of fresh leaves.

2.2.3 Hot aqueous Extracts of Fresh and dried leaves

Here, the same step was used as in cold water treatment with 30 -minutes boiling while plant material was dipped in distilled water.

\subsubsection{Ethanol (95\%) Extracts of Fresh and dried Leaves}

Here also, the same procedure was followed as in cold water treatment.

\subsection{Source and Maintenance of test Organisms}

Pure culture of Staphylococcus aureus, Streptococcus faecalis, Escherichia coli and P. aeruginosa clinically isolated from Rapha Medical Laboratory, Afikpo were used as test organisms. Pure cultures of the isolates were maintained in appropriate media for future use.

\subsection{Standardization of inoculums}

The inocula were prepared from the stock cultures, which were maintained on nutrient agar slant at $4^{0} \mathrm{C}$ and sub cultured onto nutrient broth using a sterilized wire loop. The density of the suspension inoculated onto the media for susceptibility test was determined by comparison with $0.5 \mathrm{McFarland}$ standard of barium sulphate solution (Cheesbrough, 2002)

\subsection{Antibacterial Assay}

Antibacterial activity of the seven different samples; fresh leaf juice, cold water extract of fresh leaves, hot water extract of fresh leaves, cold water extracts of dried leaves, hot water extracts of dried leaves, ethanol extracts of fresh leaves and ethanol extracts of dried leaves were individually tested against the studied organisms.

In vitro, antibacterial test was then carried out by disc diffusion method (Bauer, 1996; Barry, 1980) using $25 \mu 1$ of standardized suspension of tested bacteria $\left(10^{8} \mathrm{cfu} / \mathrm{ml}\right)$ spread on Mueller-Hilton agar plates. The dried and sterile disc $(8 \mathrm{~mm}$ in diameter) impregnated with $0.1 \mathrm{ml}$ of standard plant extracts were placed on the seeded agar plates with the aid of sterile forceps. The plates were incubated at $37^{\circ} \mathrm{C}$ for 24 hours. Antibacterial activity was evaluated by measuring in millimeter $(\mathrm{mm})$ the zones of inhibition against the tested bacteria (Bauer, 1996).

\subsection{Minimum Inhibitory Concentration (MIC)}

MIC of the different samples of the extracts of M. oleifera Lam was determined by two-fold serial dilution method. Five different concentrations of the samples were prepared, 25, 20, 15,10 and $5 \mathrm{mg} / \mathrm{ml}$. The above mentioned concentrations of the extracts were introduced into different wells bored on the sterile medium 
each containing test organisms and were inoculated for $24 \mathrm{~h}$ at $37^{\circ} \mathrm{C}$. The lowest concentration of the crude extract that showed zone of inhibition is the Minimum Inhibitory Concentration. Sterile water was used as control.

\subsection{Antibacterial Assay}

\section{Results}

The antibacterial activity of the fresh leaf juice, cold and hot water extract of fresh and dried leaves, and ethanol extracts of fresh and dried leaves of Moringa oleifera are presented in TABLES 1 and 2

Fresh leaf juice of $M$. oleifera which was sensitive to three of the tested pathogens; Streptococcus faecalis, Staphylococcus aureus and P. aeruginosa, with varying degree of inhibition. Their individual diameter zones of inhibition were, 15, 5 and $4 \mathrm{~mm}$ respectively.

Also, all the pathogens were sensitive to ethanol extracts of fresh and dried leaves with their respective diameter zones of inhibition as presented in the TABLE 1, with the exception of $E$. coli which showed no inhibition on the extract of the dried leaves.

Antibacterial activity of aqueous extracts of fresh leaves was equally demonstrated on cold water which displayed a potential effect on S. aureus and Streptococcus faecalis with diameter zone of inhibition as 10 and $8 \mathrm{~mm}$. Also, hot aqueous extracts of fresh leaves was also shown to be sensitive on $\mathrm{S}$. aureus and Streptococcus faecalis with their respective diameter zones of inhibition as 8 and $9 \mathrm{~mm}$ respectively. There was no inhibition of $E$. coli and $P$. aeruginosa from this extracts (TABLE 2).

The cold aqueous extracts of dried leaves exhibited antibacterial effect on S. aureus and Streptococcus faecalis, their diameter zones of inhibition were 9 and $7 \mathrm{~mm}$ respectively. This extracts was unable to inhibit the growth of E. coli and P. aeruginosa. Also, hot aqueous extracts of dried leaves displayed similar antibacterial effect on S. aureus and Streptococcus faecalis, and has no inhibition effect on E. coli and P. aeruginosa.

Table 1. Antibacterial activity of fresh leaf juice and ethanol extract of fresh and dried leaves of m. oleifera lam against some human pathogenic bacteria

\begin{tabular}{llcl}
\hline \multirow{2}{*}{ Bacteria } & \multicolumn{3}{c}{ Zones of inhibition diameter (mm) } \\
\cline { 2 - 4 } & Fresh Leaf Juice & $\begin{array}{c}\text { Ethanol extract of } \\
\text { Fresh leaves }\end{array}$ & Dried leaves \\
\hline S. aureus & 5 & 22 & 11 \\
S. faecalis & 15 & 11 & 20 \\
E. coli & $\mathrm{N} 1$ & 4 & $\mathrm{~N} 1$ \\
P. aeruginosa & 4 & 5 & 4 \\
\hline
\end{tabular}

Key: N1 = No Inhibition

Table 2. Antibacterial activity of aqueous extracts of fresh and dried leaves

\begin{tabular}{|c|c|c|c|c|}
\hline \multirow{4}{*}{ Bacteria } & \multicolumn{4}{|c|}{ Zones of inhibition(mm) } \\
\hline & \multicolumn{4}{|c|}{ Aqueous extracts of } \\
\hline & \multicolumn{2}{|c|}{ Fresh leaves } & \multicolumn{2}{|c|}{ Dried leaves } \\
\hline & Cold & Hot & Cold & Hot \\
\hline S. aureus & 10 & 8 & 9 & 9 \\
\hline S. faecalis & 8 & 9 & 7 & 6 \\
\hline E. coli & N1 & N1 & N1 & N1 \\
\hline P. aeruginosa & N1 & N1 & N1 & N1 \\
\hline
\end{tabular}

Key: N1 = No inhibition 


\subsection{Minimum Inhibitory Concentration (MIC)}

Minimum Inhibitory Concentration of the different extracts against the tested bacterial pathogens is shown in TABLE 3 and 4 below. The fresh leaf juice became inactive at concentration less than $15 \mathrm{mg} / \mathrm{ml}$. The highest minimum inhibition concentration was $25 \mathrm{mg} / \mathrm{ml}$ for Staphylococcus aureus, while it is $15 \mathrm{mg} / \mathrm{ml}$ for $P$. aeruginosa and $S$. faecalis. The ethanol extracts of both the fresh and dried leaves have inhibitory activity against three of the tested pathogen; S. aureus, S. faecalis and P. aeruginosa and their MIC values ranged from $15-25 \mathrm{mg} / \mathrm{ml}$. The aqueous extract of both cold and hot water extract of fresh and dried leaves were also found to be susceptible to $S$. aureus and S. faecalis and their respective MIC values ranged from $20-25 \mathrm{mg} / \mathrm{ml}$.

Table 3. Minimum Inhibitory concentration of fresh leaf juice and ethanol extract of fresh and dried leaves of $M$. oleifera lam against some human pathogenic bacteria

\begin{tabular}{|c|c|c|c|}
\hline \multirow{3}{*}{ Bacteria } & \multicolumn{3}{|c|}{ Minimum Inhibitory Concentration(mg/ml) } \\
\hline & \multicolumn{3}{|c|}{ Ethanol extract of } \\
\hline & Fresh Leaf Juice & Fresh leaves & Dried leaves \\
\hline S. aureus & 25 & 25 & 25 \\
\hline S. faecalis & 15 & 15 & 15 \\
\hline E. coli & N1 & NI & N1 \\
\hline P. aeruginosa & 15 & 15 & 15 \\
\hline
\end{tabular}

Key: N1 = No Inhibition

Table 4. Minimum Inhibitory Concentration of aqueous extracts of fresh and dried leaves

Minimum Inhibitory Concentration(mg/ml)

\begin{tabular}{|c|c|c|c|c|}
\hline \multirow[b]{3}{*}{ Bacteria } & \multicolumn{4}{|c|}{ Minimum Inhibitory Concentration(mg/ml) } \\
\hline & \multicolumn{3}{|c|}{ Aqueous extracts of } & \multirow[b]{2}{*}{ Hot } \\
\hline & $\begin{array}{l}\text { Fresh leaves } \\
\text { Cold }\end{array}$ & Hot & $\begin{array}{l}\text { Dried leaves } \\
\text { Cold }\end{array}$ & \\
\hline S. aureus & 20 & 20 & 25 & 20 \\
\hline S. faecalis & 25 & 25 & 25 & 25 \\
\hline E. coli & N1 & N1 & N1 & N1 \\
\hline P. aeruginosa & N1 & N1 & N1 & N1 \\
\hline
\end{tabular}

Key: N1 = No inhibition

\section{Discussion}

The result obtained from this work indicated that the fresh leaf juice and ethanol extracts of fresh and dried leaves have strong antibacterial activity on the organisms tested except on E. coli were it has little or no effect. Also the hot and cold aqueous extract of the fresh and dried leaves showed appreciable antibacterial activity on S. aureus and S. faecalis, while it has no effect on E.coli and P. aeruginosa

The antibacterial activity of the crude plant extracts on the test organisms justifies the active principle observed in herbal preparations. Decoction of plant parts or boiling the plants parts in water is employed on several occasions. According to this research work, preparing an extracts with ethanol was shown to provide a 
better antibacterial activity. This is because ethanol can extract the active ingredient of the plant more than aqueous extracts. This corroborates the work of Nair et al., 2005 who had similar findings. Ethanol extracts of fresh leaves was sensitive to all the tested organisms used in this study namely; Staphylococcus aureus, Streptococcus faecalis, E.coli and P. aeruginosa. Fresh leaf juice and ethanol extracts of dried leaves (TABLE 1 ), also showed relatively higher inhibitory potency on three organisms tested except E.coli, this result is in agreement with Adesokan et al., 2007 but contrary to Nari et al., 2005 whose fresh juice, was sensitive to $E$. coli. Furthermore, Staphylococcus aureus, and Streptococcus spp, has been reported to be less susceptible to plant extracts in earlier study conducted by other researchers (Kuhut et al., 1994; Afolayan and Meyer, 1995). In this research, it was observed that Staphylococcus aureus, and Streptococcus faecalis were more sensitive to the ethanol extracts, fresh leaf juice and aqueous extracts. This is in line with the findings conducted by Doughari et al., 2007. Also, in earlier research done by other researchers, hot water extracts could not inhibit any organisms, (Kuhut et al, 1994 and Afolayan 1995). But in this study, hot water extract of fresh and dried leaves were able to inhibit two organisms: Staphylococcus aureus, and Streptococcus faecalis

These consequences suggest that $M$. oleifera Lam. Leaves used, contain bioactive substances whose antibacterial potentials are highly comparable with that of antibiotic used in sensitivity test against microorganism. The activity of plants against microorganisms may be indicative of the presence of broadspectrum antibiotic compounds in that plant. Failure of some of the extracts to exert antibacterial effect on the test organism is not enough to conclude that the extract does not contain substances that can exert antibacterial activity against the test organism because the potency of the extract depends on the method used to obtain the extract (Unaeze., 1986). Research has also shown that the difference in antimicrobial properties of the plant extracts might be attributable to the age of the plant used, freshness of the plant material, physical factor (temperature, light or water), contamination by field microbes, and incorrect preparation of the plant etc. (Siddluraja and Becker, 2003; Vaghasiya and Chanda, 2007).

Today, most pathogenic organisms are becoming resistant to antibiotic (Chandarana et al., 2005). Moringa oliefera leaves have been reported to be a good source of natural antioxidants such as ascorbic acid, phenolic and carotenoids (Dillard and German, 2000). To overcome this alarming problem, the discovery of novel active compounds against new targets is a matter of urgency. Thus M. oleifera Lam. Leaves could become promising natural antimicrobial agents with potential applications in pharmaceutical industry for controlling the pathogenic bacteria.

\section{Conclusion.}

The result of this work indicated that extracts of this Plant possess inhibitory potential against the tested pathogens. The active ingredients of this plant could be enhanced if the component is purified. This plant therefore holds a promise as a potential source of new drug for treating infection caused by these clinical pathogens.

\section{References}

[1] Adesokan, A.A., Akanji, M.A and Yakubu, M.T (2007). Antibacterial potentials of aqueous extract of Enantia chlorantha stem bark. Afr. J. Biotechnol., 6(22): 2502-2505.

[2] Adriana, B., Almodovarl, A.N.M., Pereiral, C.T and. Mariangela, T.A (2007). Antibacterial efficacy of Curcuma zedoaria extract as assessed by linear regression compared with commercial mouthriness. Braz. J. Microbiol., 38: 440-445.

[3] Afolayan, A.J and Meyer, J.J.M (1995). Antibacterial activity of Helichrysum aureonitens. (Asteraceae), J. Ethnopharmacol. 47: 109-111.

[4] Akueshi, C.O., Kadiri, C.O., Akueshi, E.U., Agina, S.E and Ngurukwem, B (2002). Antimicrobial potentials of Hyptis Sauvedens poit (Lamiaccae), J. Bot. 15: 37-41.

[5] Al-Bari, M.A., Sayeed, M.A., Rahman, M.S and Mossadik, M.A (2006).Characterization and antimicrobial activities of a phenolic acid derivative produced by Streptomyces bangladeshiensis, a novel species collected in Bangladesh, Rec. J. Medicine and Med. Sci. 1: $\quad$ 77-81.

[6] Barry, A.L (1980). Procedure for testing antimicrobial agent in agar media. In Lorian V (ed) Antibiotica in Laboratory Medicines. Willims and Wikins Co. Baltimore. P. 1-23.

[7] Bauer, A. W., Kirby, W.M., Sherris, J.C and Turck, M (1986). Antibiotic susceptibility testing by a standardized single disk method. Am. J. Clin Pathol., 45(4): 493-496.

[8] Cáceres, A., Cabrera, O., Morales, O., Mollinedo, P and Mendia, P (1991). Pharmacological Action of Moringa oleifera Plant. J. Ethnopharmacol, 33: 213-216.

[9] Chandrasekaran, M and Venkatesalu, V (2004). Antibacterial activity of Syzygium jambolanum seeds, J. Ethnopharmarcol. 91: 105108 .

[10] Cheesbrough, M (2002). Medical Laboratory Manual for Tropical countries ELBS edition. Tropical Health Technology Publications, UK. 2: 2-392.

[11] Dahot, M.U (1998). Vitamin content of flowers and seeds of M.oleifera. Pak J. Biochem, 21:1-24

[12] Dilhuydy, J.M (2003). Patients' attraction to complementary and alternative Medicine (CAM): A reality which physicians can neither ignore nor deny. Bull Cancer, 90: 623-628.

[13] Dillard, C.J and German, J.B (2000). Phytochemicals: nutraceutical and human health: A review. J. Sci. Food Agr., 80: 17441756. 
[14] Doughari, J.H; El-Mahmood, A.M and Manzara, S (2007). Studies on antibacterial activity of root extracts of Carica papaya L. Afri. J. Microbiol Res, 6:037-041.

[15] Fahey, J.W (2005). Moringa oleifera: A review of the Medical evidence for its nutritional, therapeutic and prophylactic properties, Trees for Life Journal, 11: 1-5.

[16] Kawo, A.H (2007). Water purification Potential and in-vivo toxicity evaluation of the aqueous and petroleum ether extracts of Calotropis procera (Ait.F) Ait.F latex and Moringa oleifera Lam seed powder Ph.D thesis, Microbiology Unit, Department of Biological Sciences, Bayero Universty, kano 184pp.

[17] Kuhnt, M.A., Probestle, H., Rimpler, H., Bauer, R and Hei, M. (1994). Biological and pharmacological activities and further constituents of Hyptis verticillata, Planta Medica ,61: 227-232.

[18] Makonnen, E., Hunde, A and Damecha, G. (1997). Hypoglycemic effect of M. stenopetala aqueous extract in rabbits, phytother. Res, 11: 147-148.

[19] Mehta, L.K., Balaraman, R., Amin, A.H., Baffa, P.A and Gulati, O.D.(2003). Effects of fruit of M. oleifera on the lipid profile of normal hypercholesterolaemic rabbits J. Ethnopharmacol, 86: 191-195.

[20] Morton, J.F (1991). The horse radish tree: M. pterigosperma (Moringaceae). A boon to arid lands. Botany, 45: 318-333

[21] Muyibi, S.A and Evison, L.M (1995b). Optimizing physical parameters affecting coagulation of turbid water with M. oleifera seeds. Water Res., 29: 2689-2695.

[22] Nair, R., Kalariya, T and Sumitra, C (2005). Antibacterial activity of some selected Indian Medicinal Flora. Turk J. Biol., 29: 4147.

[23] Nickon, F., Saud, Z.A., Rehman, M.H and Haque, M.E (2003). In vitro antibacterial activity of the compound isolated from chloroform extract of M.oleifera lam. Pak. J. Biol. Sci., 22:1888 - 1890

[24] Pal, S.S., Mukherjee, P.K and Saha, B.P (1995a). Studies on the antiulcer activity of M. oleifera leaf extract on gastric ulcer models in rats., Phytother. Res., 9:463-465.

[25] Rebecca, H.S.U., Sharon, M., Arbainsyah, A and Lucienne, D (2006). Moringa oleifera. Medicinal and Socio-economic uses. International Course on Economic Botany. National Herbarium Leiden, Netherland. pp. 2-6.

[26] Ruckmani, K., Kavmani, S., Anandan,R and Jaykar, B .(1998). Effect of Moringa oleifera Lam on paracetamol-induced hepatoxicity. Indian J. Pharm. Sci., 60: 33-35.

[27] Rojas, J.J., Ochoa, V.J., Ocampo, S.A and Munoz, J.F (2006). Screening for antimicrobial activity of ten medicinal plants used in colombian folkloric medicine: A possible alternative in the treatment of non-nosocomial Infections. BMC complement Altem., Med. 6(2): 15-20.

[28] Sharma, P., Kumari, P., Srivastava, M.M and Srivastava, S. (2006). Removal of cadmium from aqueous system by shelled $M$. oleifera Lam seed powder. Bio. Technol., 97: 299-305.

[29] Siddhuraju, P and Becker, k (2003). Antioxidant properties of various solvent extracts of total phenolic constituents from three different agro-climatic origins of drumstick tree (Moringa oleifera Lam). J. Agri. Food Chem., 15 (8) : 2144-2155.

[30] Silver, L.L (1993). Discovery and development of new antibiotics: the problem of antibiotic resistance. Antimicrob. Agents Chemother, 37: 377-383.

[31] Unaeze, N.C and Abarikwa, P.O (1996). Antimicrobial activity of certain medicinal plant used in traditional medicine in Nigeria. A preliminary study. J. Microbiol., 69(1-2): 32-40.

[32] Vaghasiya, Y and Chanda, V.S (2007). Screening of methanol and acetone extracts of fourteen Indian medicinal plants for antimicrobial activity. Turk. J. Biol., 31: 243-248.

[33] Vijaya, K and Ananthan S (1997). Microbiological screening of Indian medicinal plants with special reference to Enteropathogens. J. Altern. Complement Med., 3: 13-20. 